\title{
DETERMINANTS OF SME ACCESS TO PUBLIC PROCUREMENT: EMPIRICAL EVIDENCE FROM THE VISEGRAD GROUP COUNTRIES
}

\author{
Peter Nemec $^{1}$, Peter Džupka ${ }^{2}$
}

\begin{abstract}
This article aims to investigate the factors influencing the success of small and medium-sized enterprises (SMEs) in public procurement in the Visegrad Group Countries. According to the European Union, tools such as the division of contracts into smaller lots or the evaluation of tenders based on the most economically advantageous tender (MEAT) increase the chances of SME's winning contracts in public procurement. In particular, the evaluation of tenders based on MEAT rather than the lowest price is a tool favoring SMEs, as it boosts their innovative potential, which creates the preconditions for achieving the best value for taxpayers' money. By analyzing more than 150,000 contract award notices published in the Tenders Electronic Daily in 2019, we found a positive effect on SMEs' chances of winning a contract when using framework agreements or dividing contracts into smaller lots. Moreover, the results of multinomial logit regression suggest that the evaluation of tenders based on MEAT rather than lowest prices increases the chances of SMEs to win the contract by more than 50\%. However, the findings that the share of SMEs in the total financial value of contracts is less than $20 \%$, with SMEs winning more than $60 \%$ of all contracts, suggest that some obstacles of SMEs' access to public contracts, such as financial, administrative or technical complexity of projects may persist and require further research.
\end{abstract}

JEL Classification Numbers: H57, O38, DOI: https://doi.org/10.12955/peb.v2.257

Keywords: public procurement, SMEs, most economically advantageous tender,

\section{Introduction}

The importance of small and medium-sized enterprises (SMEs) in terms of their economic benefits is constantly growing. According to the European Commission (2019), SMEs operating in the nonfinancial business sector accounted for 54.5\% of EU-wide GDP in 2018 and employed more than $61 \%$ of all EU employees. The significant share of SMEs in the EU economy is a good reason to research their current conditions for accessing public funds, which are spent by Member States through public procurement. The European Commission (2017) estimates that more than 1,900 billion EUR is spent on public procurement each year, representing around 14\% of EU-wide GDP. The existing literature also perceives the potential role of procurement in supporting innovation (Aschhoff \& Sofka, 2009; Edler \& Yeow, 2016) as well as the business activities of SMEs (Harland et al., 2019). The importance of SMEs is growing even more in terms of achieving sustainability goals such as inclusive, green, and economic growth. The OECD considers SMEs to be the "vehicle of inclusive growth" in terms of job creation and value creation (Koirala, 2019). In other words, SMEs that grow and innovate can push markets and other firms to invest and upgrade (European Commission, 2020; OECD, 2018). Despite the significant representation and contribution of SMEs to the EU economy, they still must overcome various obstacles to gain access to public contracts, including demanding technical, financial and administrative requirements set by contracting authorities (Loader, 2015; Schoenmaekers, 2015).

The new generation of EU procurement directives adopted in 2014 provides a framework for better value for money, as well as promoting better access to public procurement for SMEs through mechanisms such as framework agreements, dividing contracts into smaller lots or evaluating tenders using MEAT instead of the lowest price. The most economically advantageous tender (MEAT) criteria refer to the award of a contract based on the best price-quality ratio, which should include a price or cost element (European Union, 2014). The use of the best price-quality ratio as contract award criteria allows contracting authorities to refrain from strict adherence to precise technical specifications and helps to get the best value for money in a broader perspective. It also serves as a tool for better involvement of SMEs in public procurement because it provides opportunities for SMEs to also compete in the field of quality, as they can use their specialization, flexibility, and innovation potential.

The aim of this article is to examine the impact of selected determinants representing some elements of the procurement process on the chances of SMEs to win public contracts. It is a tender evaluation based on MEAT, which is the center of our research, as the quality evaluation spurs the innovative potential of SMEs and thus creates the preconditions for obtaining the best value for money in public

\footnotetext{
${ }^{1}$ Technical University of Košice, Faculty of Economics, Department of Regional Sciences and Management, peter.nemec@tuke.sk, ORCID: 0000-0002-6067-6788

${ }^{2}$ Technical University of Košice, Faculty of Economics, Department of Regional Sciences and Management, peter.dzupka@tuke.sk, ORCID: 0000-0001-8947-6555
} 
procurement. The research is based on a dataset comprising the contracts awarded by contracting authorities in Visegrad countries and published in the Tenders Electronic Daily in 2019.

The paper is structured as follows: First, a brief overview of related literature is provided in Section 2. In Section 3, we present the data and the methodology employed. The results are presented in Section 4 and are discussed, together with conclusions, in Section 5.

\section{Literature overview}

Given the important role of small and medium-sized enterprises in the EU economy, they must be seen as an important counterpart for contracting authorities. The low involvement of SMEs in public procurement has so far been the subject of several studies. Some researchers have identified various barriers faced by SMEs in public procurement, while others have focused on identifying tools to overcome these barriers in order to increase SME participation in public procurement (Flynn \& Davis, 2016; Loader, 2013, 2015). Akenroye et al. (2020) categorize the factors causing low SME involvement in public procurement as external and internal factors. Typical examples of external factors hindering the better involvement of SMEs in public procurement can be seen in slow payments, poorly written tender documents or inadequate financial and technical requirements set by contracting authorities (Cabras, 2011; Loader, 2005, 2007; Peck \& Cabras, 2011). However, the lack of specialized knowledge (Karjalainen \& Kemppainen, 2008) or marketing skills (Walker \& Preuss, 2008) also play a role in hampering the performance of SMEs in public procurement. Important concerns were raised, in particular, about the size of contracts, which are generally too complex for SMEs, as well as the length of contracts or too much focus on that prices must be low (e.g., Loader, 2005, 2007; Morand, 2003; Nielsen, 2017). The technical and economic requirements imposed on tenderers relate to the size and complexity of the contracts, as they must take into account both the subject matter of the contract and its estimated value. Therefore, in the context of the adequacy of the requirements for tenderers, the division of contracts into smaller lots is considered as one of the tools to improve SMEs' access to contracts (European Commission, 2019a). Dividing the contract into several smaller lots allows SMEs to bid more and therefore have a higher chance of winning the contract (Maréchal \& Morand, 2012). Hoekman \& Taş (2020), in an analysis of a large EU public procurement dataset, found that dividing contracts into smaller lots with values less than $€ 25,000$ increases the probability of SMEs winning such contracts.

As mentioned above, focusing on the lowest price instead of value for money by contracting authorities is another and no less significant barrier to SME access to public procurement markets (Loader, 2015; Nielsen, 2017). Recent studies examining the effects of MEAT on SMEs suggest that quality evaluation in procurement may not have a positive effect on SMEs in all EU countries. Stake (2017), using procurement data from Sweden from 2006-2008, argues that evaluating quality can be counterproductive since it increases large firms' bids and success rates. However, a recent study by the European Commission (2019a) suggests that the use of the best price-quality ratio in tender evaluation has a positive effect on the likelihood of SMEs winning a contract in Central and Eastern European countries. Although the effects of MEAT on SMEs may vary, there is no doubt that the evaluation of quality in public procurement contributes to better value for money compared to awarding contracts based on the sole criterion of the lowest price. Rewarding the quality can also serve as an opportunity for SMEs to get their specialized products on the table, the quality of which can often outweigh their higher price.

\section{Data description and Methodology}

The dataset is based on the contract notices of Slovak, Czech, Hungarian and Polish contracting authorities, which were published by TED in 2019. TED serves as a platform for publishing information on public procurement contracts for the European Economic Area, Switzerland and the Republic of Macedonia. The contract data obtained from the EU open data portal ${ }^{3}$ contains the data resulting from their conversion from the electronic forms used by contracting authorities to send notices concerning tenders. Contracting authorities are obliged to publish tenders as well as other information related to tenders whenever the estimated value of the contract exceeds the EU thresholds for public procurement. For the analyzed period, the main advertising thresholds values were $€ 221,000$ for supplies and services

\footnotetext{
${ }^{3}$ TED subsets in CSV format are available on https://data.europa.eu/euodp/en/data/dataset/ted-csv
} 
( $€ 144,000$ for Government Departments and Offices) and $€ 5,548,000$ for works. Although the estimated value of many contracts reported in the TED may appear below the threshold, it should be noted that the value of all related or similar goods, services or works procured by the contracting authority during the period must be taken into account when calculating the estimated value of the contract. It is therefore not uncommon to see contracts published in TED, with the estimated value of them in many cases is far below the EU procurement thresholds.

The original data sample, used for the purpose of our research, consists of 705,196 contract award notices sent to TED for publication in 2019 by contracting authorities across the EU. Of these, we excluded notices with no information about SMEs $(7,307)$, submitted offers $(1,377)$ or those which were later cancelled. Then we used only notices on contracts awarded by contracting authorities from countries belonging to the Visegrad Group. The final dataset, which we analyzed for the purpose of this research, consisted of 153,349 contract award notices, of which every single notice corresponds to an individual contract awarded by the contracting authority to the individual supplier. Table 1 contains the summary and short description of all variables considered in our research.

\begin{tabular}{|l|l|}
\hline \multicolumn{1}{|c|}{ Table 1: Summary of variables } \\
\hline Variable & \multicolumn{1}{c|}{ Description } \\
\hline Winner category & $\begin{array}{l}\text { Our dependent variable, which indicates whether the contract was awarded } \\
\text { to an SME, a large company or a group of tenderers composed of SMEs and } \\
\text { large companies. }\end{array}$ \\
\hline Award criteria & $\begin{array}{l}\text { Indicates the method of evaluation of tenders used by the contracting } \\
\text { authority for the award of the contract; contains the criteria of the lowest } \\
\text { price and the most economically advantageous tender }\end{array}$ \\
\hline Divided into lots & Binary variable that indicates whether the procurement was divided into lots. \\
\hline Framework agreement & $\begin{array}{l}\text { Denotes whether procurement involved the establishment of a framework } \\
\text { agreement }\end{array}$ \\
\hline Type of contract & $\begin{array}{l}\text { Indicates whether the subject of the contract was services, supplies or } \\
\text { construction works }\end{array}$ \\
\hline Joint procurement & $\begin{array}{l}\text { Indicates whether the contract was awarded in procurement carried out by } \\
\text { several contracting authorities }\end{array}$ \\
\hline $\begin{array}{l}\text { Awarded by Central } \\
\text { Body }\end{array}$ & $\begin{array}{l}\text { Contract was awarded by contracting authority providing centralized } \\
\text { purchasing activities }\end{array}$ \\
\hline EU funds & Denotes whether the contract is co-financed by the EU funds \\
\hline Source: Authors elaboration from TED CSV open data (European Union, 2020b) \\
\hline
\end{tabular}

According to the EU's assessment within the EU Single Market scoreboard, the countries of the Visegrad Group are characterized by a relatively low share of contracts awarded based on the MEAT evaluation. The use of the lowest price criterion in countries such as Slovakia and the Czech Republic in 2019 is $81 \%$ and $95 \%$, respectively, of all contracts awarded (European Union, 2020a). Table 2 provides data on the distribution of contracts by country. The data (Table 2) confirm the relatively low use of the MEAT evaluation, especially in the case of Slovakia, where the share of contracts entered in this way represents only $6 \%$ of all contracts in the dataset used by us. In the case of the Czech Republic, the share of contracts awarded based on the MEAT evaluation is slightly better (15\%), while Poland and Hungary award half or more of all contracts using the MEAT evaluation.

\begin{tabular}{|l|l|r|r|r|}
\hline \multicolumn{5}{|l|}{ Table 2: Contract distribution by countries } \\
\hline & \multicolumn{1}{|c|}{ Total } & MEAT evaluation & Lowest price evaluation \\
\cline { 2 - 5 } & Slovak Republic & 2,861 & 170 & 2,691 \\
\cline { 2 - 5 } & Czech Republic & 25,519 & 4,011 & 21,508 \\
\cline { 2 - 5 } & Hungary & 7,928 & 4,518 & 3,410 \\
\cline { 2 - 5 } & Poland & 117,086 & 58,126 & 58,960 \\
\hline
\end{tabular}

The contract data in Table 3 indicate the breakdown of contracts by the award criterion used, which is slightly in favor of the lowest price criterion (56\%). On the other hand, when comparing the financial value, more than $60 \%$ of the total financial value was distributed through contracts awarded based on the MEAT evaluation. 


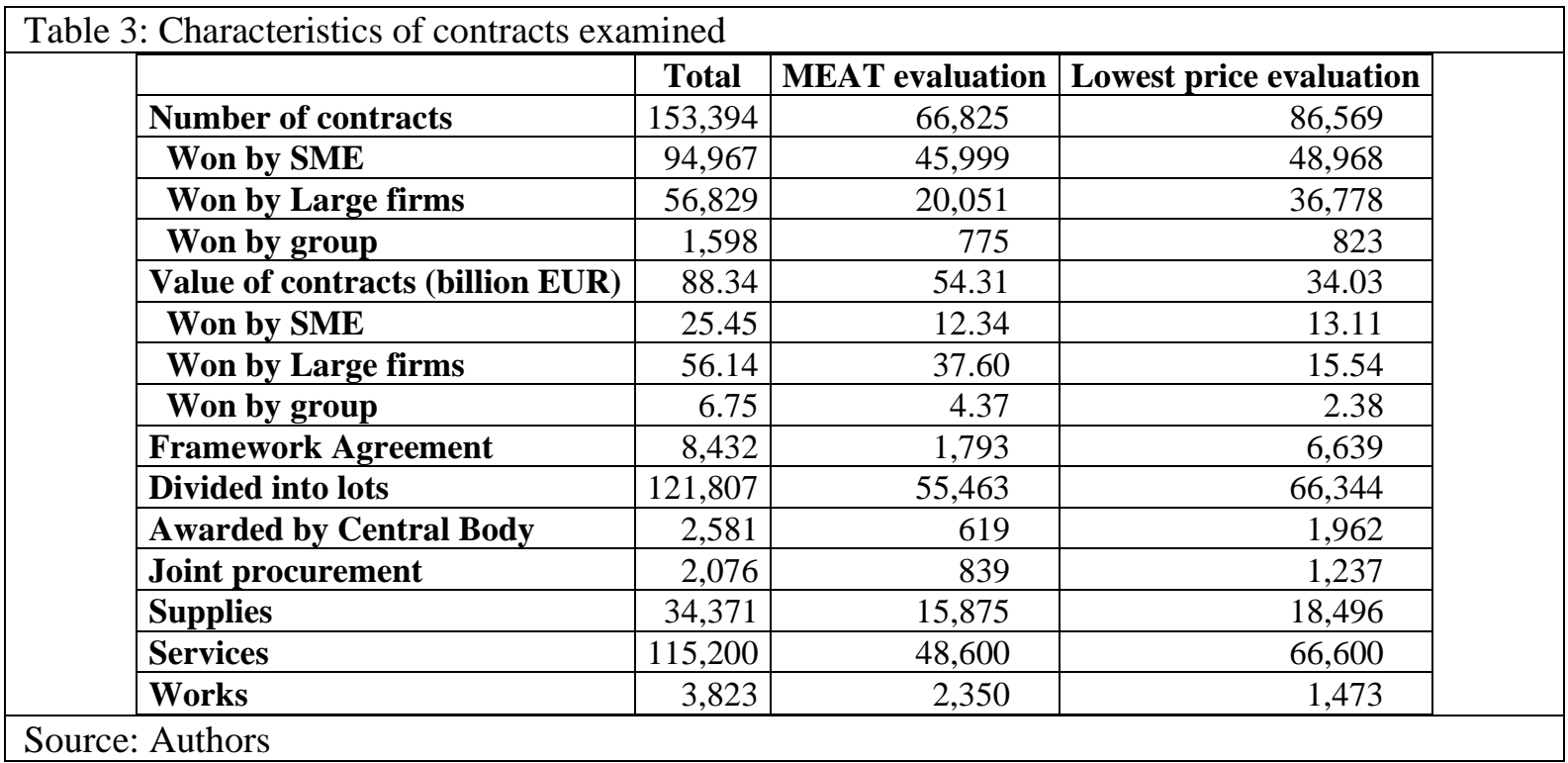

Another important issue to be pointed out is the significant disproportion between the share of SMEs in the contracts won and their financial value. While SMEs have won more than $60 \%$ of all contracts in the data set, the financial value of these contracts represents only $29 \%$ of the total financial value.

The basic research question is how selected elements of public procurement affect the chances of SMEs winning a contract. We assume that the use of MEAT increases the chances of SMEs winning a contract. The second assumption is that the use of joint procurement, as well as the award of contracts by central procurement bodies, reduces the chances of SMEs to win contracts, as these elements are often used to make savings from large contracts, which are one of the barriers to access public procurement.

To answer the above research question, we employ the multinomial logit model. We believe that the use of multinomial logit rather than binary logit allows us to observe the effects on the third category of winners, which is a group of SMEs and large firms.

\begin{tabular}{|c|c|c|c|c|c|}
\hline Variable & $\operatorname{Exp}(\mathbf{B})$ & Std. Error & Sig. & $\operatorname{Exp}($ B) CI LB & $\operatorname{Exp}($ B) CI UB \\
\hline \multicolumn{6}{|l|}{ Group of SME and LF's } \\
\hline Divided into lots & 1.012 & 0.062 & 0.847 & 0.896 & 1.143 \\
\hline MEAT evaluation & 1.681 & 0.053 & 0.000 & 1.516 & 1.863 \\
\hline Frame Agreement & 2.347 & 0.081 & 0.000 & 2.003 & 2.749 \\
\hline Services & 0.349 & 0.091 & 0.000 & 0.292 & 0.417 \\
\hline Supplies & 0.100 & 0.090 & 0.000 & 0.083 & 0.119 \\
\hline Joint procurement & 1.053 & 0.149 & 0.730 & 0.787 & 1.408 \\
\hline Awarded by Central Body & 0.385 & 0.263 & 0.000 & 0.230 & 0.646 \\
\hline EU funds & 1.174 & 0.092 & 0.083 & 0.979 & 1.407 \\
\hline \multicolumn{6}{|l|}{ SME contractor } \\
\hline Divided into lots & 1.042 & 0.015 & 0.006 & 1.012 & 1.073 \\
\hline MEAT evaluation & 1.613 & 0.011 & 0.000 & 1.577 & 1.649 \\
\hline Framework Agreement & 1.024 & 0.025 & 0.332 & 0.976 & 1.075 \\
\hline Services & 1.678 & 0.041 & 0.000 & 1.549 & 1.818 \\
\hline Supplies & 0.758 & 0.040 & 0.000 & 0.702 & 0.820 \\
\hline Joint procurement & 0.351 & 0.048 & 0.000 & 0.320 & 0.386 \\
\hline Awarded by Central Body & 0.703 & 0.042 & 0.000 & 0.648 & 0.784 \\
\hline EU funds & 2.947 & 0.022 & 0.000 & 2.825 & 3.074 \\
\hline Large firms (default) & - & - & - & - & 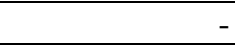 \\
\hline
\end{tabular}

\section{Results}

The results of the multinomial logit are presented in Table 4 . We can observe a significant positive effect of our main explanatory variable (MEAT evaluation) in the case of both groups of winners, which include SMEs. The use of the MEAT evaluation increases the probability that the winner of the tender 
will be an SME or a group including SMEs by $61 \%$ and $68 \%$, respectively. Abandoning the lowest price as the only award criterion and admitting quality as another element of the evaluation process seems to be a way to increase the chances of SMEs winning these contracts.

The framework agreement variable coefficient shows a significant positive effect in the case of the group of winners consisting of Large firms and SMEs, while in the group consisting only of SMEs it is not statistically significant. As expected, the award of contracts through joint procurement reduces the likelihood of SMEs obtaining a contract by $65 \%$. The same applies to the award of contracts by central bodies, where the probability of an SME winning a contract is reduced by $30 \%$ and $62 \%$, respectively. As in these cases, the needs of several contracting authorities accumulate into contracts which thus increase in size; it seems that it is the financial size or the excessive complexity of these contracts that may adversely affect the success of SMEs.

Regarding the type of contract, the results suggest that the procurement of services increases the probability that an SME will win a contract by almost $68 \%$ compared to works. The division of contracts into smaller lots shown a subtle but positive effect on SMEs' chances of winning the contract.

The strongest impact on the probability of SMEs winning a tender is that the contract is co-financed by EU funds. However, we will not draw any conclusions from this yet, as further and more detailed research is needed, focusing on the individual elements of these contracts.

\section{Conclusion}

The main aim of this paper was to examine the impact of various elements of the procurement process on SMEs' chances of winning contracts in the Visegrad Group countries. The results suggest that there is still a disproportion between the number of contracts won by SMEs and the share of SMEs in the total financial value distributed through public procurement. SMEs received only $29 \%$ of the total financial value while winning $60 \%$ of all contracts.

The results of the multinomial logit regression confirmed our original assumptions that SMEs will benefit from a quality evaluation, as their chances of winning the contract increase by more than $60 \%$. The results also confirm the recent findings of the European Commission (2019a) on the positive correlation of the MEAT evaluation to the winning of contracts by SMEs in the countries of Central and Eastern Europe. Our assumptions were also confirmed in the case of joint procurement and contracts awarded by the central authority, as these significantly reduce the probability of SMEs winning a contract. Therefore, in order to improve SMEs' access to public procurement, it is recommended that contracting authorities consider the more frequent use of the MEAT evaluation when awarding contracts.

The limitations of this study can be seen in the fact that it does not consider the relative weight of the individual qualitative or price criteria used in the MEAT evaluation. Further research should therefore focus on the evaluation formulas used by contracting authorities to award contracts based on the best price-quality ratio, such as the relative weight of price and quality criteria. It would be beneficial to conduct further research focused on contracts co-financed by EU funds, as the results suggest, such contracts have a significant impact on SMEs.

\section{References}

Akenroye, T. O., Owens, J. D., Elbaz, J., \& Durowoju, O. A. (2020). Dynamic capabilities for SME participation in public procurement. Business Process Management Journal, 26(4), 857-888. https://doi.org/10.1108/BPMJ-10-2019-0447

Aschhoff, B., \& Sofka, W. (2009). Innovation on demand-Can public procurement drive market success of innovations? Research Policy, 38(8), 1235-1247. https://doi.org/10.1016/j.respol.2009.06.011

Cabras, I. (2011). Mapping the spatial patterns of public procurement. International Journal of Public Sector Management, 24(3), 187-205.

Edler, J., \& Yeow, J. (2016). Connecting demand and supply: The role of intermediation in public procurement of innovation. Research Policy, 45(2), 414-426. https://doi.org/10.1016/j.respol.2015.10.010

European Commission. (2020). An SME Strategy for a sustainable and digital Europe.

https://eur-lex.europa.eu/legal-content/EN/TXT/?uri=CELEX:52020DC0103

European Commission. (2017). European Semester: Thematic factsheet - Public procurement - 2017.

https://ec.europa.eu/info/sites/default/files/file_import/european-semester_thematic-factsheet_public-procurement_en_0.pdf

European Commission. (2019a). Analysis of the SMEs' participation in public procurement and the measures to support it 697/PP/GRO/IMA/18/1131/10226. Final report.

https://ec.europa.eu/docsroom/documents/42102/attachments/1/translations/en/renditions/native 
European Commission. (2019b). Annual report on European SMEs 2018/2019 : research \& development and innovation by SMEs.

https://op.europa.eu/en/publication-detail/-/publication/cadb8188-35b4-11ea-ba6e-01aa75ed71a1/language-en

European Parliament. (2014). Directive 2014/24/EU of The European Parliament and of The Council of 26 February 2014 on public procurement and repealing Directive 2004/18/EC (Text with EEA relevance). Official Journal of the European Union, 94/65, 65-242. https://doi.org/10.5040/9781509923205.0008

European Union. (2020a). Public Procurement - Performance per Policy Area - The Single Market Scoreboard - European Commission.

https://ec.europa.eu/internal_market/scoreboard/performance_per_policy_area/public_procurement/index_en.htm

European Union. (2020b). TED CSV open data Notes and Codebook. https://data.europa.eu/euodp/en/data/dataset/tedcsv/resource/99798664-6cf7-4429-b53c-4ecac59f1b6a

Flynn, A., \& Davis, P. (2016). The policy-practice divide and SME-friendly public procurement. Environment and Planning C: Government and Policy, 34(3), 559-578. https://doi.org/10.1177/0263774X15614667

Harland, C., Telgen, J., Callender, G., Grimm, R., \& Patrucco, A. (2019). Implementing Government Policy in Supply Chains: An International Coproduction Study of Public Procurement. Journal of Supply Chain Management, 55(2), 6-25. https://doi.org/10.1111/jscm.12197

Hoekman, B., \& Taş, B. K. O. (2020). Procurement policy and SME participation in public purchasing. Small Business Economics. https://doi.org/10.1007/s11187-020-00414-Z

Karjalainen, K., \& Kemppainen, K. (2008). The involvement of small- and medium-sized enterprises in public procurement: Impact of resource perceptions, electronic systems and enterprise size. Journal of Purchasing and Supply Management. https://doi.org/10.1016/j.pursup.2008.08.003

Koirala, S. (2019), "SMEs: Key drivers of green and inclusive growth", OECD Green Growth Papers, No. 2019/03, OECD Publishing, Paris, https://doi.org/10.1787/8a51fc0c-en.

Loader, K. (2005). Supporting SMEs through Government Purchasing Activity. The International Journal of Entrepreneurship and Innovation, 6(1), 17-26. https://doi.org/10.5367/0000000053026383

Loader, K. (2007). The challenge of competitive procurement: Value for money versus small business support. Public Money and Management. https://doi.org/10.1111/j.1467-9302.2007.00601.x

Loader, K. (2013). Is public procurement a successful small business support policy? A review of the evidence. Environment and Planning C: Government and Policy, 31(1), 39-55. https://doi.org/10.1068/c1213b

Loader, K. (2015). SME suppliers and the challenge of public procurement: Evidence revealed by a UK government online feedback facility. Journal of Purchasing and Supply Management, 21(2), 103-112.

https://doi.org/10.1016/j.pursup.2014.12.003

Maréchal, F., \& Morand, P. H. (2012). Small business participation procurement policy: Subcontracting vs allotment. Recherches Economiques de Louvain, 78(2), 5-23. https://doi.org/10.3917/rel.782.0005

Morand, P. H. (2003). SMES and public procurement policy. Review of Economic Design, 8(3), 301-318. https://doi.org/10.1007/s10058-003-0104-0

Nielsen, W. (2017). Technical Report: Policies that Promote SME Participation in Public Procurement. Technical Report: Business Environment Working Group, September.

Peck, F., \& Cabras, I. (2011). The Impact of Local Authority Procurement on Local Economies: The Case of Cumbria, North West England. Public Policy and Administration. https://doi.org/10.1177/0952076709356859

Schoenmaekers, S. (2015). The role of SMEs in promoting sustainable procurement. Sustainable Public Procurement Under EU Law, 2014(May), 160-181. https://doi.org/10.1017/cbo9781316423288.010

Stake, J. (2017). Evaluating quality or lowest price: consequences for small and medium-sized enterprises in public procurement. Journal of Technology Transfer, 42(5), 1143-1169. https://doi.org/10.1007/s10961-016-9477-4

Walker, H., \& Preuss, L. (2008). Fostering sustainability through sourcing from small businesses: public sector perspectives. Journal of Cleaner Production, 16(15), 1600-1609. https://doi.org/10.1016/j.jclepro.2008.04.014 